\title{
Table of legislation - Tabla de legislación
}

\section{ARGENTINA $^{1}$}

Ley 26.361 que modifica la ley 24.240 de defensa del consumidor (Boletín Oficial 7.4.2008).

\section{AUSTRALIA $^{2}$}

Competition and Consumer Act 2010, Schedule 2 .273

Diplomatic Privileges and Immunities Act 1967

Foreign States Immunities Act 1985 .306 306

\section{CANADA $^{3}$}

Constitution Act 1982 . .95

Criminal Code .285

State Immunity Act, RSC 1985 .306

State Immunity Act ....................................306

Reference re Supreme Court Act, RSC 1985 (Canada), 2014 SCC 21

\section{COLOMBIA $^{4}$}

Constitución Política de la República de Colombia de 1991 (Gaceta Constitucional 20.7.1991).

1 La legislación de la República Argentina puede encontrarse en <www.tsj.gob.ve/gacetaoficial>.

2 Australian federal legislation and regulations are available on <www.australia.gov. au/information-and-services/public-safetyand-law/legislation>. Most state and territorial governments have similar information available through their websites.

3 Canadian federal legislation and regulations are available on $<$ http://laws.justice.gc.ca/ eng/>. Most provincial and territorial governments have similar information available through their websites.

4 Puede accederse a la legislación colombiana en <www.gacetaoficial.gov.py/list. php?tipo $=2>$.

\section{ENGLAND (UNITED KINGDOM) ${ }^{5}$}

Access to Justice Act 1999, Schedule 3........151

Administration of Justice Act $1969 \ldots \ldots \ldots \ldots . .158$

Arbitration Act 1975

$104,302,354$

Arbitration Act 1996. 395,436

Asylum and Immigration (Treatment of

Claimants, etc) Act 2004 292

Borders, Citizenship and Immigration Act 2009

Companies Act 2006 300

Companies (Audit, Investigation and Community Enterprise) Act 2004 301

Constitutional Reform Act 2005 150,164

Consumer Protection Act 1987. 279

Contracts (Rights of Third Parties) Act 1999

Coroners and Justice Act 2009 389

Corporate Manslaughter and Corporate

Homicide Act 2007. 285,300

Criminal Justice Act 2003, Schedule 2 151

Criminal Justice and Public Order Act 1994 390

Criminal Procedure and Investigations Act 1996

Data Protection Act 1998 .........................299

Defamation Act 2013.......... 157, 276, 279, 382

Diplomatic Privileges Act 1964 ....................306

European Communities Act 1972 ...... 104, 163, 302,354

European Public Limited-Liability Company Regulations 2004 (SI 2004 No 2326).... 301

European Union Act 2011 ...................94, 271

Financial Services and Markets Act 2000 ...300

Fraud Act 2006 284,300 Human Rights Act 1998 .......... 89-90, 94, 96-7, $107-9,149,266,271,272,303$

Immigration Act 1971 292

Immigration and Asylum Act 1999 292

Immigration, Asylum and Nationality Act 2006 292

Insolvency Act 2000 300

Interpretation Act 1978 100

5 English legislation is available at <www. legislation.gov.uk>. 
Judicial Committee Act 1833 ......................149

Juries Act 1974_........................................152

Law of Libel Amendment Act 1888 ............102

Limited Liability Partnership Act 2000........301

Limited Partnerships Act 1907....................301

Magna Carta .................................89-90, 271

Nationality, Immigration and Asylum Act 2002

292

Occupiers' Liability Act $1957 \ldots \ldots . . .96, \mathbf{1 6 1 , 2 7 8}$

Occupiers' Liability Act 1984.........96, 161, 278

Partnership Act 1890 ................................301

Proceeds of Crime Act $2000 \ldots \ldots \ldots \ldots \ldots \ldots \ldots \ldots . . . . .389$

Prosecution of Offences Act 1985 ................150

Regulation of Investigatory Powers Act 2000

.389

Sales of Goods Act 1979

274

Senior Courts Act 1981 ..................... 157, 382

Sexual Offences Act 2003............................283

State Immunity Act 1978 ..................................306

Supreme Court of Judicature Act 1873 ........48,

72-3

Theft Act 1968

.284

Terrorism Act 2000

389

Unfair Contract Terms Act 1977 .........98, 171,

$172-6,273,639$

UK Borders Act 2007

.292

Youth Justice and Criminal Evidence Act 1999

390

Civil Procedure Rules ${ }^{6} . . .91,156,378,443,643$

Criminal Procedure Rules ${ }^{7} . . . .91$, 152, 388, 390

Family Procedure Rules 8

.91

Immigration Rules...

.292

Practice Direction (Hansard: Citation)

[1995] 1 All ER 234 103

\section{EUROPEAN UNION ${ }^{9}$}

Convention determining the State responsible for examining application

6 The Civil Procedure Rules are available at (UK Justice) <www.justice.gov.uk/courts/ procedure-rules/civil/rules $>$.

7 The Criminal Procedure Rules are available at (UK Legislation) <www.legislation.gov. uk/uksi/2013/1554/contents/made>.

8 The Family Procedure Rules are available at (UK Justice) <www.justice.gov.uk/courts/ procedure-rules/family>.

9 European Union legislation is available at <http://ec.europa.eu/legislation/index en.htm>; see also <http://eurlex.europa.eu/ for asylum lodged in one of the member

States of the European Communities, drafted at Dublin 15 June, 1990, 30 ILM 425 (1991) 293

Tratado de Funcionamiento de la Unión Europea (TFUE). $125,130,131,189$, 194, 332, 339, 347, 356

Tratado de la Unión Europea (TUE o

Tratado de Maastricht).... 124, 130, 131, 339

Tratado de Lisboa ......................................131

Tratado de Roma …………...........................130

Treaty on European Union (TEU or

Maastricht Treaty) ..........94, 271-2, 291, 304

Treaty on the Functioning of the European Union (TFEU) .......94, 105, 272, 291, 298-9,

Treaty of Lisbon 300,304

Treaty of Rome

94,272

Communication from the Commission to the European Parliament, the Council, the European Economic and Society Committee and the Committee of the Regions, A Common European Sales Law to Facilitate Cross-Border Transactions in the Single Market, $\operatorname{COM(2011)~} 636$ final (11 October 2011)

Council Directive 90/364 of June 28, 1990 on the right of residence, [1990] OJ L $180 / 26$

Council Directive 2005/85/EC on minimum standards on procedures in Member States for granting and withdrawing refugee status, [2005] OJ L 326/13 ...

Council Regulation (EC) 1/2003 of 16 December 2002 on the implementation of the rules on competition laid down in Articles 81 and 82 of the Treaty, [2003] OJ L $1 / 1$.

Council Regulation (EEC) $2137 / 85$ of 25 July 1985 on the European Economic Interest Grouping (EEIG), [1985] OJ L199/1

Decisión del Consejo 2003/93/CE, de 19 de diciembre de 2002, por la que se autoriza a los Estados miembros a firmar, en interés

homepage.html;jsessionid=7QCsTDYcJlGL 4TTFkqT1KcTpLVQyTgz1kyHfdwWm7W x02yFFn8YB!-1639360510?locale=en $>$. Hay también una recopilación de disposiciones transpuestas por la UE en: Derecho Nacional (Eur-Lex) <http://eur-lex.europa.eu/collection/ n-law.html?locale $=$ es $>$. 
de la Comunidad, el Convenio de La Haya de 1996 relativo a la competencia, la ley aplicable, el reconocimiento, la ejecución, la cooperación en materia de responsabilidad parental y de medidas de protección de los niños [2003] DO L 48/1..131

Decisión marco del Consejo 2002/584/

JAI, de 13 de junio de 2002, relativa a la orden de detención europea y a los procedimientos de entrega entre Estados miembros [2002] DO L 190/1

Directiva 77/249/CEE del Consejo de las Comunidades Europeas, de 22 de marzo de 1977, dirigida a facilitar el ejercicio de la libre prestación de servicios por los abogados [1977] DO L 78/17.

Directiva 85/374/CEE del Consejo de las Comunidades Europeas, de 25 de julio de 1985 , relativa a la aproximación de las disposiciones legales, reglamentarias y administrativas de los Estados Miembros en materia de responsabilidad por los daños causados por productos defectuosos [1985] DO L 210/29

Directiva 93/13/CEE del Consejo de las Comunidades Europeas, de 5 de abril de 1993, sobre las cláusulas abusivas en los contratos celebrados con consumidores [1993] DO L 95/29 $324-5$

Directiva 95/46/CE del Parlamento Europeo y del Consejo, de 24 de octubre de 1995, relativa a la protección de las personas físicas en lo que respecta al tratamiento de datos personales y a la libre circulación de estos datos [1995] DO L 281/31.

Directiva 97/7/CE del Parlamento

Europeo y del Consejo, de 20 de mayo de 1997, relativa a la protección de los consumidores en materia de contratos a distancia [1997] DO L 144/19.

Directiva 98/5/CE del Parlamento Europeo y del Consejo, de 16 de febrero de 1998, destinada a facilitar el ejercicio permanente de la profesión de abogado en un Estado miembro distinto de aquél en el que se haya obtenido el título [1998] DO L 77/36

Directiva 2003/86/CE del Consejo, de 22 de septiembre de 2003, sobre el derecho a la reagrupación familiar [2003] DO L 251/12.

Directiva 2003/109/CE del Consejo, de 25 de noviembre 2003, relativa al estatuto de los nacionales de terceros países residentes de larga duración [2004] DO L 16/44 .... ..340
Directiva 2004/35/CE del Parlamento

Europeo y del Consejo, de 21 de abril de 2004, sobre responsabilidad medioambiental en relación con la prevención y reparación de daños medioambientales [2004] DO L 143/56 ....328

Directiva 2004/38/CE del Parlamento Europeo y del Consejo, de 29 de abril de 2004, relativa al derecho de los ciudadanos de la Unión y de los miembros de sus familias a circular y residir libremente en el territorio de los Estados miembros [2004] DO L 229/35 ...339

Directiva 2004/48/CE del Parlamento Europeo y del Consejo, de 29 de abril de 2004, relativa al respecto de los derechos de propiedad intelectual [2004] DO L $157 / 45$

Directiva 2005/36/CE del Parlamento Europeo y del Consejo, de 7 de septiembre de 2005, relativa al reconocimiento de cualificaciones profesionales [2005] DO L $255 / 22$

Directiva 2008/52/CE del Parlamento Europeo y del Consejo, de 21 de mayo de 2008, sobre ciertos aspectos de la mediación en asuntos civiles y mercantiles [2008] DO L 136/3...

Directiva 2008/115/CE del Parlamento

Europeo y del Consejo, de 16 de diciembre de 2008 , relativa a normas y procedimientos comunes en los Estados miembros para el retorno de los nacionales de terceros países en situación irregular [2008] DO L 348/98.

Directiva 2010/64/CE del Parlamento

Europeo y del Consejo, de 20 de octubre de 2010, sobre el derecho a interpretación $\mathrm{y}$ traducción en los procesos penales [2010] DO L280/1

Directiva 2011/77/EU del Parlamento

Europeo y del Consejo, de 27 de septiembre de 2011, por la que se modifica la Directiva 2006/116/CE relativa al plazo de protección del derecho de autor y determinados derechos afines [2011] DO L 265/1

Directiva 2011/95/UE del Parlamento

Europeo y del Consejo, de 13 de diciembre de 2011, por la que se establecen normas relativas a los requisitos para el reconocimiento de nacionales de terceros países o apátridas como beneficiarios de protección internacional, a un estatuto uniforme 
para los refugiados o para las personas con derecho a protección subsidiaria y al contenido de la protección concedida (refundición) [2011] DO L 337/9 .... 340

Directiva 2012/13/UE del Parlamento Europeo y del Consejo, de 22 de mayo de 2012, relativa al derecho a la información en los procesos penales [2012] DO L 142/1

Directiva 2012/28/UE del Parlamento Europeo y del Consejo, de 25 de octubre de 2012, sobre ciertos usos autorizados de las obras huérfanas [2012] DO L $299 / 5$ $406-7$

Directiva 2013/11/UE del Parlamento Europeo y de Consejo, de 21 de mayo de 2013, sobre resolución de litigios en línea en materia de consumo [2013] DO L $165 / 1$

Directiva 2013/32/UE del Parlamento Europeo y del Consejo, de 26 de junio de 2013, sobre procedimientos comunes para la concesión o la retirada de la protección internacional (refundición) [2013] DO L $180 / 60$.

Directiva 2013/33/UE del Parlamento

Europeo y del Consejo, de 26 de junio de 2013, por la que se aprueban normas para la acogida de los solicitantes de protección internacional (texto refundido) [2013] DO L 180/96 340

Directiva 2014/65/UE del Parlamento Europeo y del Consejo relativa a los mercados de instrumentos financieros y por la que se modifican la Directiva 2002/92/CE y la Directiva 2011/61/UE (refundición) [2014] DO L 173/349. 121

Directiva 2014/104/UE del Parlamento Europeo y del Consejo, de 26 de noviembre de 2014, relativa a determinadas normas por las que se rigen las acciones por daños en virtud del Derecho nacional, por infracciones del Derecho de la competencia de los Estados miembros y de la Unión Europea [2014] DO L 349/1

European Directive 2010/64 on the right to interpretation and translation in criminal proceedings [2010] OJ L280/1. 382

European Parliament and Council Directive 95/46/EC of 24 October 1995 on the protection of individuals with regard to the processing of personal data and on the free movement of such data, [1995] OJ L $281 / 31$
European Parliament and Council Directive 2004/38 on the right of citizens of the Union and their family members to move and reside freely within the territory of the Member States, [2004] OJ L 229/35 .........291

European Parliament and Council Regulation (EC) 583/2008 of 4 July 2008 on the Law Applicable to Contractual Obligations, [2008] OJ L 177/6

Propuesta de reglamento relativo a una normativa común de compraventa europea, presentada en Bruselas el 11 de octubre de 2011 [COM (2011) 635 final].

Reglamento (CE) $1 / 2003$, de 16 diciembre 2002 sobre la aplicación de las normas de competencia previstas en los artículos 81 y 82 del Tratado [2003] DO L 1/1

Reglamento (CE) 343/2003 del Consejo, de 18 de febrero de 2003, por el que se establecen los criterios y mecanismos de determinación del Estado miembro responsable del examen de una solicitud de asilo presentada en uno de los Estados miembros por un nacional de un tercer país (Dublín II) [2003] DO L50/1

Reglamento (CE) 583/2008, de 4 de julio de 2008 , relativo a la ley aplicable a las obligaciones contractuales [2008] DO L $177 / 6$

Reglamento (CE) 861/2007 del Parlamento Europeo y del Consejo, de 11 de julio de 2007 , por el que se establece un proceso europeo de escasa cuantía [2007] DO L 199/1 409, 469

Reglamento (CE) 864/2007 del Parlamento Europeo y del Consejo, de 11 de junio de 2007, relativo a la ley aplicable a las obligaciones extracontractuales [2007] DO L 199/40 ...................................................328

Reglamento (CE) 1206/2001 del Consejo, de 28 de mayo de 2001, relativo a la cooperación entre los órganos jurisdiccionales de los Estados miembros en el ámbito de la obtención de pruebas en materia civil o mercantil [2001] DO L $174 / 1$

Reglamento (CE) 1346/2000 del Consejo, de 29 de mayo de 2000 , sobre procedimientos de insolvencia [2000] DO L 160/1 189

Reglamento (CE) 1393/2007 del

Parlamento Europeo y del Consejo, de 13 de noviembre de 2007, relativo a la notificación y al traslado en los Estados miembros de documentos judiciales y 
extrajudiciales en materia civil o mercantil

[2007] DO L 324/79 405

Reglamento (CE) 1435/2003 del Consejo, de 22 de julio de 2003, relativo al Estatuto de la sociedad cooperativa europea (SCE) [2003] DO L 207/1 348

Reglamento (CE) 1896/2006 del Parlamento Europeo y del Consejo, de 12 de diciembre de 2006, por el que se establece un proceso monitorio europeo [2006] DO L 339/1 409

Reglamento (CE) 2157/2001 del Consejo, de 8 de octubre de 2001, por el que se aprueba el Estatuto de Sociedad Anónima Europea (SE) [2001] DO L 294/1.... 348

Reglamento (CE) 2201/2003 del Consejo, de 27 de noviembre de 2003, relativo a la competencia judicial, el reconocimiento y la ejecución de resoluciones judiciales en materia matrimonial y por responsabilidad parental, por el que se deroga el Reglamento (CE) 1347/2000 [2003] DO L 338/1

Reglamento (CEE) 492/2011 del Parlamento Europeo y del Consejo, de 5 de abril de 2011, relativo a la libre circulación de los trabajadores dentro de la Unión (Texto pertinente a efectos del EEE) [2011] DO L $141 / 1$ 339

Reglamento (CEE) 2137/85 del Consejo, de 25 de julio de 1985, relativo a la constitución de una agrupación europea de interés económico (AEIE) [1985] DO L $199 / 1$

Reglamento (UE) 4/2009 del Consejo, de 18 de diciembre de 2008, relativo a la competencia, la ley aplicable, el reconocimiento y la ejecución de resoluciones y la cooperación en materia de obligaciones de alimentos [2009] DO L 7/1

Reglamento (UE) 524/2013 del Parlamento Europeo y del Consejo, de 21 de mayo de 2013, sobre resolución de litigios en línea en materia de consumo [2013] DO L $165 / 63$

Reglamento (UE) 650/2012 del Parlamento Europeo y del Consejo, de 4 de julio de 2012, relativo a la competencia, la ley aplicable, el reconocimiento y la ejecución de las resoluciones, a la aceptación y la ejecución de los documentos públicos en materia de sucesiones mortis causa y a la creación de un certificado sucesorio europeo [2012] DO L 201/107. 125,189 , 608,609
Reglamento (UE) 1215/2012 del Parlamento Europeo y del Consejo, de 12 de diciembre, relativo a la competencia judicial, el reconocimiento y la ejecución de resoluciones judiciales en materia civil y mercantil [2012] DO L 351/1 ..... 126, 189, 192

\section{IRELAND $^{10}$}

Constitution

Liability for Defective Products Act 1991 ...276

\section{MEXICO $^{11}$}

Constitución Política de los Estados Unidos Mexicanos (DOF 5.2.1917) (CPEUM).....32, $114,115,117,118,119,120,121$, $122,126,127,128,131,132,188$, 197, 198, 201, 204, 207, 210, 320, $321,322,331,332,335,342,350$, $353,355,358,417,468$

Código Civil Federal (DOF 26.5.1928, 14.7.1928, 3.8.1928 y 31.8.1928) (CCF)...120, $210,323,327,328,329,330,351$

Código de Comercio (DOF 7.10.1889 a 13.12.1889) $119,120,347,350$,

Código de Justicia Militar (DOF 31.8 $424,467,468$ 1933) 331

Código Federal de Procedimientos Civiles (DOF 24.2.1943) (CFPC) ........ 191, 210, 243, $412,470,472-3,474$

Código Federal de Procedimientos Penales (DOF 30.8.1934) 120,417

Código Nacional de Procedimientos Penales

(DOF 5.5.2014) (CNPP). 120,333 , 417-20, 421

Código Penal Federal (DOF 14.8.1931)

(CPF) ... 35, 120, 332, 333, 336, 337, 471, 479

Ley de ahorro y crédito popular (DOF 4.6.2001).... 125

Ley de Amparo, reglamentaria de los artículos 103 y 107 de la Constitución

10 Irish legislation is available at $<w w w$. irishstatutebook.ie/home.html>.

11 Se puede acceder a las normas federales mexicanas y a parte de las estatales en $<\mathrm{http} / /$ www.diputados.gob.mx>. Las páginas webs oficiales de los distintos estados también suelen contener una sección normativa. 
Política de los Estados Unidos Mexicanos (DOF 2.4.2013) ..204, 206, 210, 213, 410, 481

Ley de concursos mercantiles (DOF 12.5.2000). .352

Ley de extradición internacional (DOF 29.12.1975) .421

Ley de migración (DOF 25.5.2011)..... 118, $\mathbf{3 4 2}$

Ley de Nacionalidad (DOF 23.1.1998) ........342

Ley de Protección al Usuario de Servicios Financieros (DOF 18.1.1999). .210

Ley del servicio exterior mexicano (DOF 4.1.1994) .357

Ley Federal contra la Delincuencia Organizada (DOF 7.11.1996).... 332

Ley Federal de Competencia Económica (DOF 23.5.2014) 210,353

Ley Federal de Protección al Consumidor de 24 de diciembre de 1992 (DOF 24.12.1992) $137-40,210,468-9$

Ley Federal de Responsabilidad Ambiental (DOF 7.6.2013) 328

Ley Federal de Responsabilidad Patrimonial del Estado (DOF 31.12.2004). .207

Ley Federal del Trabajo (DOF 1.4.1970)...121,

Ley Federal en Materia de Delitos Electorales (DOF 23.5.2014) $210,243,328$

Ley General de Equilibrio Ecológico y de Protección del Medio Ambiente (DOF 28.1.1988). 332

Ley General de Población (DOF 7.1.1974) 342

Ley General de Sociedades Cooperativas (DOF 3.8.1994) 352

Ley General de Sociedades Mercantiles (DOF 4.8.1934) .351

Ley Nacional de Mecanismos Alternativos de Solución de Controversias en Materia Penal (DOF, 29.12.2014) .332

Ley Orgánica del Poder Judicial de la Federación (DOF 26.5.1995) (LOPJF)...187, $188,193,194,210$

Ley Orgánica del Tribunal Federal de Justicia Fiscal y Administrativa (DOF 6.12.2007) .206

Ley Orgánica de la Administración Pública Federal (DOF 29.12.1976) .132

Ley Orgánica de la armada de México (DOF 30.12.2002) 118

Ley Orgánica de la Procuraduría general de la República (DOF 29.5.2009) 30, 198

Ley sobre la celebración de Tratados (DOF 2.1.1992) $131,132,355$

Ley sobre refugiados, protección complementaria y asilo político (DOF 27.1.2011) 342
Reglamento de la Ley de aeropuertos (DOF 17.2.2000).............................................118

Reglamento de la Ley de migración (DOF 28.9.2012)................................................342

Reglamento de la Ley de nacionalidad (DOF 17.6.2009) 342

Reglamento de la Ley general de población (DOF 14.4.2000). 342

Constitución Política del Estado Libre y Soberano de Guerrero (CPELSG) (Periódicos Oficiales del Estado de Guerrero, 3.11.1917, 10.11.1917, 17.11.1917 y 5.1 .1918$)$ 120

Constitución Política del Estado de Jalisco (Periódico Oficial del Estado de Jalisco, 21.7.1917, 25.7.1917, 28.7.1917, 1.8.1917).

Código Civil para el Distrito Federal (DOF 26.5.1928). 323,483

Código de Procedimientos Civiles para el Distrito Federal (DOF 1-21.09.1932) (CPCDF) 191, 196, 201, 202, 209, 243, 409, 410-11, 412, 475, 485

Código Penal para el Distrito Federal (GODF 16.7.2002) 332

Ley del Tribunal de lo ContenciosoAdministrativo del Distrito Federal (DOF 19.12.1995). .206

Ley Orgánica del Tribunal Superior de Justicia del Distrito Federal (DOF 7.2.1996) 188,193

Ley Orgánica del Poder Judicial del Estado de Sonora (DO 12.12.1996) 188

\section{NEW ZEALAND ${ }^{12}$}

Accident Compensation Act 2001..............276

New Zealand Bill of Rights Act 1990, s 4.....95, 266

\section{PUERTO RICO}

Código Penal de 18 de junio de 2004 337

12 New Zealand legislation is available at $<w w w . l e g i s l a t i o n . g o v t . n z />$ 


\section{SPAIN $^{13}$}

Constitución española, de 28 de diciembre de 1978 (BOE 29.12.1978) (CE)..... 114, 115, $116-7,123,127,131,132-3,187$, 194, 198, 199, 201, 209, 243, 318, $319,320,324-5,328,331,335$, 338-9, 340, 341, 348, 349, 350, $356,404,405,406,408,409,416$, 467,469

Ley Orgánica 1/1996, de 15 de enero, de protección jurídica del menor, de modificación parcial del Código civil y de la Ley de enjuiciamiento civil (BOE 17.1.1996). 199,415

Ley Orgánica 1/2014, de 13 de marzo, de modificación de la Ley Orgánica 6/1985, de 1 de julio, del Poder Judicial, relativa a la justicia universal (BOE 14.3.2014)

Ley Orgánica 2/1979, de 3 de octubre, del Tribunal Constitucional (BOE 5.10.1979) 127, 135, 194

Ley Orgánica 2/1980, de 18 de enero, sobre regulación de las distintas modalidades de referéndum (BOE 23.1.1980).

Ley Orgánica 4/1987, de 15 de julio, de la Competencia y Organización de la Jurisdicción Militar (BOE 18.7.1987)......192

Ley Orgánica 4/2000, de 11 de enero, sobre derechos y libertades de los extranjeros en España y su integración social (BOE 12.1.2000) $116,126,138$

Ley Orgánica 4/2013, de 28 de junio, de reforma del Consejo General del Poder Judicial, por la que se modifica la Ley Orgánica 6/1985, de 1 de julio, del Poder Judicial (BOE 29.6.2013) 187, 342, 349, 467

Ley Orgánica 5/1985, de 19 de junio, del Régimen Electoral General (BOE 20.6.1985) 331

Ley Orgánica 5/1995, de 22 de mayo, del Tribunal del Jurado (BOE 23.5.1995)......193

Ley Orgánica 5/2000, de 12 de enero, reguladora de la responsabilidad penal del menor (BOE 13.1.2000). 331,413

Ley Orgánica 6/1985, de 1 de julio, del Poder Judicial (BOE 2.7.1985) (LOPJ)....187

Ley Orgánica 7/2015, de 21 de julio, por la

13 Véase (n 2). En Noticias Jurídicas <http:// noticias.juridicas.com/> es posible obtener información legislativa actualizada. que se modifica la Ley Orgánica 6/1985, de 1 de julio, del Poder Judicial (BOE 22.7.2015). 194, $403-4$

Ley Orgánica 10/1995 del Código Penal español (BOE 24.11.1995) .........119, 197, 479

Ley Orgánica 12/1995, de 12 de diciembre, de represión del contrabando (BOE 13.12.1995).

Ley Orgánica 13/1985, de 9 de diciembre, de Código Penal Militar (BOE 11.12.1985)...331

Ley Orgánica 16/1984, de 19 de julio, reguladora del proceso de habeas corpus (BOE 26.5.1984)

Ley Orgánica 18/2003, de 10 de diciembre, de cooperación con la Corte Penal Internacional (BOE 11.12.2003)....

Ley $1 / 1996$, de 10 de enero, de asistencia jurídica gratuita (BOE 12.1.1996).... 199, 415

Ley $1 / 2000$, de 7 de enero de enjuiciamiento civil (BOE 8.1.2000) (LEC) 119, 404

Ley $4 / 1985$, de 21 de marzo, de extradición pasiva (BOE 26.3.1985)

Ley 4/1987, de 15 de julio, de competencia y organización de la jurisdicción militar (BOE 18.7.1987)

Ley $5 / 2012$, de 6 de julio, de mediación en asuntos civiles y mercantiles (BOE 7.7.2012). 201, 467

Ley 5/2015, de 27 de abril, de modificación de la LECRIM (BOE 28.4.2015) 416

Ley $7 / 1985$, de 2 de abril, reguladora de las bases del régimen local (BOE 3.4.1985)...116

Ley 7/1998, de 13 de abril, de condiciones generales de la contratación (BOE 14.4.1998) 137-8

Ley 11/2007, de 22 de junio, de acceso electrónico de los ciudadanos a los servicios públicos (BOE 23.6.2007) 468

Ley 14/2013, de 27 de septiembre, de apoyo a los emprendedores y su internacionalización (BOE 28.9.2013) ....342,

Ley 15/2015, de 2 de julio, de Jurisdicción Voluntaria (BOE 3.7.2015).......201, 404, 468

Ley 18/2011, de 5 de julio, reguladora del uso de las tecnologías de la información y la comunicación en la Administración de Justicia (BOE 6.7.2011)

Ley 22/2003, de 9 de julio, concursal (BOE 10.7.2003) $119,469,555$

Ley $25 / 2014$, de 27 de noviembre, de Tratados y otros Acuerdos Internacionales (BOE 28.11.2014).. 130, 355, 356,357

Ley 26/1984, de 19 de julio, general para la 
defensa de los consumidores y usuarios (BOE 24.7.1984).

Ley 29/1998, de 13 de julio, reguladora de la Jurisdicción Contencioso-Administrativa (BOE 14.7.1998). .191

Ley 29/2015, de 30 de julio, de cooperación jurídica internacional en materia civil (BOE 31.7.2015). 404, 405

Ley 34/2006, de 30 de octubre, sobre el acceso a las profesiones de abogado y procurador de los tribunales (BOE 31.8. 2006) 31

Ley 36/2011, de 10 de octubre, reguladora de la Jurisdicción Social (BOE 11.10.2011)

Ley 40/1979, de 10 de diciembre, sobre régimen jurídico de control de cambios (BOE 13.12.1979). 331

Ley 60/2003, de 23 de diciembre, de Arbitraje (BOE 36.12.2003)......422, 424, 467

Proyecto de Ley Orgánica sobre privilegios e inmunidades de los Estados extranjeros, las Organizaciones Internacionales con sede u oficina en España y las Conferencias y Reuniones internacionales celebradas en España (BOCG Serie A 10.8.2015) 358

Real Decreto de 3 de febrero de 1881, de promulgación de la Ley de Enjuiciamiento Civil (Gaceta 5.2.1881) 404,467

Real Decreto de 14 de septiembre de 1882, aprobatorio de la Ley de enjuiciamiento criminal (Gaceta 17.9.1882) (LECRIM)... $119,191,255$

Real Decreto de 22 de agosto de 1885, por el que se publica el Código de Comercio (Gaceta 16.10.1885). 119,347

Real Decreto de 24 de julio de 1889, por el que se publica el Código Civil (Gaceta 25.7.1889) (CC)

Real Decreto Legislativo 1/2007, de 16 de noviembre, por el que se aprueba el texto refundido de la Ley general para la defensa de los consumidores y usuarios y otras leyes complementarias (BOE 20.11.2007)

116,210

Real Decreto Legislativo 1/2010, de 2 de julio, por el que se aprueba el texto refundido de la Ley de sociedades de capital (BOE 3.7.2010) ....

Real Decreto Legislativo 781/1986, de 18 de abril, por el que se aprueba el Texto Refundido de las disposiciones legales vigentes en materia de régimen local (BOE 22.4.1986).
Real Decreto 99/2011, de 28 de enero, por el que se regulan las enseñanzas oficiales de doctorado (BOE 10.2.2011). .247

Real Decreto 103/2014, de 21 de febrero, por el que se adaptan determinadas normas en el ámbito del derecho de establecimiento y de la libre prestación de servicios, con motivo de la adhesión de la República de Croacia, y por el que se modifican determinadas normas relativas al reconocimiento de cualificaciones profesionales (BOE 10.3.2014) ....

Real Decreto 150/2014, de 7 de marzo, por el que se modifica el Reglamento de la Ley 34/2006, de 30 de octubre, sobre el acceso a las profesiones de Abogado y Procurador de los Tribunales, aprobado por el Real Decreto 775/2011, de 3 de junio (BOE 8.3.2014)Real Decreto 160/1997, de 7 de febrero, por el que se aprueban los Estatutos de la Comisión General de Codificación (BOE 27.2.1997).

Real Decreto 231/2008, de 15 de febrero, por el que se regula el sistema arbitral de consumo (BOE 25.2.2008). 202,468

Real Decreto 557/2011, de 20 de abril, por el que se aprueba el Reglamento de la Ley Orgánica 4/2000, sobre derechos y libertades de los extranjeros en España y su integración social, tras su reforma por Ley Orgánica 2/2009 (BOE 30.4.2011) ....116

Real Decreto 658/2001, de 22 de junio, por el que se aprueba el Estatuto General de la Abogacía Española (BOE 10.7.2001) ....34

Real Decreto 775/2011, de 3 de junio, por el que se aprueba el Reglamento de la Ley 34/2006, de 30 de octubre, sobre el acceso a las profesiones de Abogado y Procurador de los Tribunales (BOE 16.6.2011).

Real Decreto 967/2014, de 21 de noviembre, por el que se establecen los requisitos y el procedimiento para la homologación y declaración de equivalencia a titulación y a nivel académico universitario oficial y para la convalidación de estudios extranjeros de educación superior, $\mathrm{y}$ el procedimiento para determinar la correspondencia a los niveles del marco español de cualificaciones para la educación superior de los títulos oficiales de Arquitecto, Ingeniero, Licenciado, Arquitecto Técnico, Ingeniero Técnico y Diplomado (BOE 22.11.2014) 
Real Decreto 1062/1988, de 16 de septiembre, por el que se modifica el Real Decreto 607/1986, de 21 de marzo, de desarrollo de la Directiva del Consejo de las Comunidades Europeas de 22 de marzo de 1977, encaminada a facilitar el ejercicio efectivo de la libre prestación de servicios por los Abogados (BOE 21.9.1998)

Real Decreto 1467/2007, de 2 de noviembre, por el que se establece la estructura del bachillerato y se fijan sus enseñanzas mínimas (BOE 6.11.2007)

Real Decreto 1837/2008, de 8 de noviembre, por el que se incorporan al ordenamiento jurídico español la Directiva 2005/36/ CE, del Parlamento Europeo y del Consejo, de 7 de septiembre de 2005, y la Directiva 2006/100/CE, del Consejo, de 20 de noviembre de 2006, relativas al reconocimiento de cualificaciones profesionales, así como a determinados aspectos del ejercicio de la profesión de abogado (BOE 20.11.2008)

Real Decreto-ley 11/2012, de 30 de marzo, de medidas para agilizar el pago de las ayudas a los damnificados por el terremoto, reconstruir los inmuebles demolidos e impulsar la actividad económica de Lorca (BOE 31.3.2012) .....116

Reglamento 2/1995, de 7 de junio, de la Escuela Judicial (BOE 13.7.1995)

Decreto $416 / 2008$ por el que se establece la ordenación y las enseñanzas correspondientes al bachillerato en Andalucía (BOJA 149, 28.7.2008) ....

Ley 9/2009 reguladora de los Concejos Abiertos (BOA 30.12.2009 y BOE 4.2.2010)

Decreto Legislativo 1/2011, de 22 de marzo, del Gobierno de Aragón, por el que se aprueba el 'Código del Derecho Foral de Aragón' (BOA 29.3.2011)

Ley $2 / 2006$, de 14 de junio, de derecho civil de Galicia (BOE 11.8.2006)

Ley $5 / 2005$, de 25 de abril, reguladora del recurso de casación en materia de derecho civil de Galicia (DOG 18.5. 2005)

Ley 13/1989, de 10 de octubre, de montes vecinales en mano común (DOG 20.10.1989 y BOE 9.2.1990)

Decreto Legislativo 79/1990, de 6 de septiembre, por el que se aprueba el Texto Refundido de la Compilación del .323
Derecho Civil de las Islas Baleares (BOIB 2.10.1990). 323

Ley $1 / 1973$, de 1 de marzo, por la que se aprueba la Compilación del Derecho Civil

Foral de Navarra (BOE 7.3.1973) 323

Ley 3/1992, de 1 de julio, del Parlamento Vasco, del Derecho Civil Foral del País Vasco (BOE 15.2.2012) 323

Acuerdo de 28 de abril de 2011, del Pleno del Consejo General del Poder Judicial, por el que se aprueba el Reglamento 2/2011, de 28 de abril, de la Carrera Judicial (BOE 9.5.2011). 192

\section{UNITED STATES ${ }^{14}$}

US Constitution $.41,90,92,99,105-7$, $109,145,147,266,267-8,271$, 272, 286, 287-8, 290-91, 297, 303, $386,387-8,638,639$

Alternative Dispute Resolution Act of 1998, Public L No 105-315, 112 Stat 2993, 2994 (codified at 28 USC ss 651-58 (2013))......437

Foreign Corrupt Practices Act, Public Law No 95-213, 91 Stat 1494 (1977) (codified as amended in scattered sections of title 15 of the United States Code) ... 59, 85, 500, 520

Immigration and Nationality Act, Pub L No 82-414, 66 Stat 163 (1952) (codified as amended at 8 CFR s 207.2(c)) ......... 288, 343

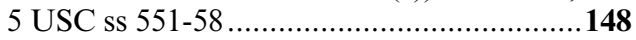
8 USC ss 1101-537 ....................................288

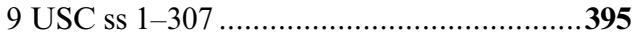

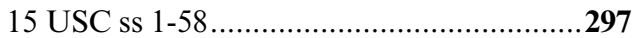

17 USC s 506 .......................................282

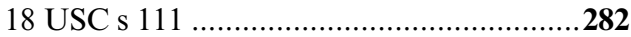

18 USC s 1963........................................285

14 US federal legislation since 1973 is available on the US government website. See Legislation (The US Congress) <http://beta. congress.gov/legislation $>$. More complete information is available from a site hosted by Cornell University. See Cornell University $<$ www.law.cornell.edu/uscode/text $>$. Other federal materials are available at United States Code (Office of the Law Revision Counsel) $<$ http://uscode.house.gov/> and US e-CFR (Government Printing Office) <www.ecfr.gov/ cgi-bin/ECFR?page=browse $>$. Most state governments make state statutes and regulations available through their websites. 
22 USC s 2370

22 USC s $254 \mathrm{~b}$ .306

28 USC s 652

28 USC s 1332.

28 USC s 1441

28 USC s 1447

28 USC ss $1602-11$

28 USC s 1782.

28 USC s 1827.

28 USC ss 2072-74

Federal Rules of Civil Procedure ${ }^{15} \ldots . . .13,148$ $158,370-71,372,380,382,384$, 437, 440, 442, 444

Federal Rules of Criminal Procedure ${ }^{16}$........93, $148,384,388,442$

Federal Rules of Evidence ${ }^{17}$ $93,98,148$ $371,375,378,384,388$

California Constitution $92,93,95$

Texas Constitution 147

California Civil Procedure Code.

Delaware Limited Liability Company Act....98

New York Civil Practice Law and Rules ....147 Utah Code Annotated 147

\section{VENEZUELA $^{18}$}

Constitución de la República Bolivariana de Venezuela de 1999 (Gaceta Oficial 30.12.1999)

15 The Federal Rules of Civil Procedure are a rule of court, rather than legislation. The Rules are available on (US Courts) <www. uscourts.gov/uscourts/rules/civil-procedure. pdf>.

16 The Federal Rules of Criminal Procedure are a rule of court, rather than legislation. The Rules are available on (US Courts) <www. uscourts.gov/uscourts/rules/criminal-procedure.pdf>.

17 The Federal Rules of Evidence are a rule of court, rather than legislation. The Rules are available on (US Courts) $<$ http://www.uscourts. gov/uscourts/rules/rules-evidence.pdf $>$.

18 La legislación de la República Bolivariana de Venezuela se puede consultar en <www.tsj. gob.ve/gaceta-oficial>.

\section{INTERNATIONAL ${ }^{19}$}

Agreement Relating to the Headquarters of the United Nations, 26 June 1947, 11 UNTS 11

Convención Americana de Derechos Humanos, hecha en San José, Costa Rica, 7-22 de noviembre de 1969 (DOF 7.5.1981)

Convención de Ginebra sobre el Estatuto de los Refugiados, GA Res 428 (V) (28 July 1951), UN Doc A/5/20, 189 UNTS $150 \ldots 207$

Convención de Naciones Unidas contra el tráfico ilícito de estupefacientes y sustancias psicotrópicas, hecha en Viena el 20 de diciembre de 1988, 1582 UNTS 95 (BOE 10.11.1990). 190

Convención de Naciones Unidas sobre el derecho del mar, hecha en Montego Bay el 10 de diciembre de 1982 (BOE 14.2.1997), 1833 UNTS 3

Convención de Naciones Unidas sobre el derecho de los tratados entre Estados y Organizaciones internacionales o entre Organizaciones internacionales, hecha en Viena el 21 de marzo de 1986, Doc. A/ CONF.129/15....

Convención de Naciones Unidas sobre el derecho de los tratados, hecha en Viena el 23 de mayo de 1969, 1155 UNTS 331 ......356

Convención de Naciones Unidas sobre el reconocimiento y la ejecución de las sentencias arbitrales extranjeras, abierto a la firma el 10 de junio de 1958, 330 UNTS 38

Convención de Naciones Unidas contra la delincuencia organizada internacional, hecha en Nueva York el 15 de noviembre de 2000, adoptada por Resolución A/ $\mathrm{RES} / 55 / 25$ de 15 de noviembre de 2000 en la 55a sesión de la Asamblea General de las Naciones Unidas (BOE 29.9.2003).....190

Convención de Naciones Unidas sobre la protección de los derechos de todos los trabajadores migratorios y de sus familiares, hecha en Nueva York el 18 de diciembre de 1990, 2220 UNTS 3.

Convención de las Naciones Unidas sobre las inmunidades jurisdiccionales de los

19 Los textos generados por la OEA están accesibles en <http://www.oas.org > y los de CNUDMI en <http://www.uncitral.org $>$. 
Estados y de sus bienes, Resolución de la Asamblea General 59/38, anexo (2 diciembre 2004).

Convención de Naciones Unidas sobre los contratos de compraventa internacional de mercaderías, hecha en Viena el 11 de abril de 1980, 1489 UNTS 3 (This is only in the English section)....

Convención de Naciones Unidas sobre los derechos del niño, hecha en Nueva York el 20 de diciembre de 1989, 1577 UNTS $3 . . .333$

Convención de Naciones Unidas sobre Prerrogativas e Inmunidades, 13 febrero 1946, 1 UNTS 15.

Convención de Viena sobre relaciones consulares, abierta a la firma el 24 de abril de 1963, 596 UNTS 26 357

Convención de Viena sobre relaciones diplomáticas, abierta a la firma el 18 de abril de 1961, 500 UNTS 95.

Convención interamericana sobre arbitraje comercial internacional, hecha en Panamá el 30 de enero de 1975. 405-6

Convención interamericana sobre competencia en la Esfera Internacional para la Eficacia Extraterritorial de las Sentencias Extranjeras, hecha en Montevideo el 8 de mayo de 1979 (DOF 28.8.1987).

Convención interamericana sobre eficacia extraterritorial de las sentencias y laudos arbitrales extranjeros, hecha en Montevideo el 8 de mayo de 1979 (DOF 20.8.1987).

Convención interamericana sobre exhortos o cartas rogatorias, hecha en Panamá el 30 de enero de 1975 $405-6$

Convenio de La Haya sobre la notificación o traslado en el extranjero de documentos judiciales y extrajudiciales en materia civil y mercantil, abierto a la firma el 15 de noviembre 1965, 658 UNTS 163

Convenio de La Haya sobre obtención de pruebas en el extranjero en materia civil y mercantil, abierto a la firma el 18 de marzo de 1970, 847 UNTS 231

Convenio europeo sobre arbitraje comercial internacional, hecho en Ginebra el 21 de abril de 1961 (BOE 4.10.1975).

Convenio internacional sobre la constitución de un fondo internacional de indemnización de daños debidos a contaminación por hidrocarburos, hecho en Bruselas el BOE 4.10.1975, 1956 UNTS 255 .
Convenio internacional sobre responsabilidad civil nacida de daños debidos a contaminación por hidrocarburos, hecho en Bruselas el 29 de noviembre de 1969, 973 UNTS 3

Convenio OIT No 182 sobre la prohibición de las peores formas de trabajo infantil y la acción inmediata para su eliminación, hecho en Ginebra el 17 de junio de 1999

Convention on the Privileges and Immunities of the United Nations, 13 February 1946.

Convention on the Service Abroad of Judicial and Extrajudicial Documents in Civil or Commercial Matters, opened for signature 15 November 1965

Convention on the Settlement of Investment Disputes Between States and Nationals of Other States, opened for signature 18 March 1965

Convention on the Taking of Evidence Abroad in Civil or Commercial Matters, opened for signature 18 March 1970 ........372

Convenio para la protección de los derechos humanos y las libertades fundamentales, hecho en Roma el 4 de noviembre de 1950, 213 UNTS 221 Convenio relativo a la supresión gradual de las fronteras comunes, hecho en Schengen el 19 junio 1990, ILM (1991) 68 168, 445

Convenio sobre acuerdos de elección de foro, hecho en La Haya el 30 de junio de 2005 [2009] DO L 133/1, Conferencia de la Haya. 189-90

Convenio sobre arreglo de diferencias relativas a inversiones entre Estados y nacionales de otros Estados, abierto a la firma el 18 de marzo de 1965, 575 UNTS 159

Convenio sobre aspectos civiles de la sustracción internacional de menores, hecha en La Haya el 25 de octubre de 1980 (BOE 24.8.1987)

Convenio sobre la ley aplicable a las obligaciones contractuales, abierto a la firma el 19 de junio de 1980, 1605 UNTS 80

Convention on the Law Applicable to

Contractual Obligations 1980, opened for

signature 19 June 1980

Estatuto del Tribunal Internacional de Justicia, aprobado en la Conferencia de San Francisco de 6 de junio de 1945 (BOE 16.11.1990), 188 UNTS 137 
Estatuto de la Corte Penal Internacional, aprobado en Roma el 17 de julio de 1998 (BOE 27.5.2002), 2187 UNTS 3

European Convention for the Protection of Human Rights and Fundamental Freedoms (European Convention on Human Rights), opened for signature 4 November 1950 94, 97, 149, 235, 303, 389,638

Pacto Internacional de Derechos Civiles y Políticos, hecho en Nueva York el 19 de diciembre de 1966, 999 UNTS 171 200 Naciones Unidas contra el tráfico ilícito de migrantes por tierra, mar y aire, hecho en Nueva York el 15 de noviembre de 2000, 2241 UNTS 507 (BOE 10.12.2003) .190

Protocolo sobre el estatuto de los refugiados, hecho en Nueva York el 31 de enero de 1967, 606 UNTS 267.

Tratado para la Constitución de un Mercado Común, hecho en Asunción el 26 de marzo de 1991, ILM (1991) 1041 ...317

United Nations Convention on Contracts for the International Sales of Goods, opened for signature 11 April 1980, 1489

UNTS 3.

194 United Nations Convention on Jurisdictional Immunities of States and Their Property, General Assembly Resolution 59/38, annex (2 December 2004)

United Nations Convention on the Recognition and Enforcement of Foreign Arbitral Awards, opened for signature 10 June 1958, 330 UNTS 38 $104,302,395$

United Nations Convention on the Settlement of Investment Disputes Between States and Nationals of Other States, opened for signature $18 \mathrm{March}$ 1965, 575 UNTS 159

United Nations Convention on the Status of Refugees, opened for signature 28 July 1951, 189 UNTS 150

Vienna Convention on Consular Relations, opened for signature 24 April 1963, 596 UNTS 261 304, 305

Vienna Convention on Diplomatic Relations, opened for signature 18 April 1961, 500 UNTS 95 305 